\title{
Raça e psicanálise no Brasil. 0 ponto de origem: Arthur Ramos
}

G uilherme Gutman

\footnotetext{
Abordagem das relações, no Brasil, entre a psicanálise e o conceito de "raça" na obra de Arthur Ramos. Estudo da relação entre os trabalhos etnográficos de Nina Rodrigues e de Arthur Ramos. Pesquisa da formação étnica, religiosa e cultural do brasileiro.

Palavras-chave: Psicanálise, raça, Arthur Ramos, cultura
} 
Elucidar o estado originário é sempre assunto de construção.

Sigmund Freud

A pureza é um mito.

Hélio Oiticica

Na cidade do Rio de Janeiro há duas ruas cujos nomes homenageiam dois médicos: o maranhense Raimundo Nina Rodrigues e o alagoano Arthur Ramos. Se a geografia urbana das ruas do Rio tivesse algum compromisso com a história das idéias no Brasil, a Rua Nina Rodrigues no Jardim Botânico, e a Rua Professor Arthur Ramos no Leblon estariam certamente no mesmo bairro. Contudo, mais difícil é saber, caso realmente estivessem no mesmo bairro, se seriam ruas paralelas ou perpendiculares, uma em relação à outra; se formariam uma mesma rua que apenas troca de nome a partir de um determinado ponto; se, ao contrário, estariam localizadas em extremos opostos do bairro ou, ainda, se em contradição direta com a primeira afirmação deste texto, deveriam estar como estão: uma no Leblon e a outra no Jardim Botânico. ${ }^{1}$

As relações entre esses dois médicos - pensadores importantes para a infindável questão "o que faz o Brasil, Brasil” - não são simples à primeira vista. Nina Rodrigues (1862-1906), sem nunca o ter sabido foi pai

1. É certo que as ruas recebem os seus nomes em função de uma certa notoriedade de seus homenageados e do tratamento dado pela posteridade em favor da permanência desses nomes. Mas vencida essa etapa, o nome na placa ganha certa autonomia, atuando simultaneamente como registro histórico e como uma nova matriz de difusão do homenageado. 
intelectual de Ramos (1903-1949) e deu origem a uma "escola” de pensamento que frutificou em idéias, ações e instituições pelos estados da Bahia, de São Paulo e do Rio de Janeiro. Arthur Ramos, filho pródigo de Nina (e não “o mais humilde dos discípulos", como ele certa vez se auto proclamou), foi um dos que, da década de 1930 em diante, retornou aos textos do mestre. ${ }^{2}$ A prodigalidade de Ramos se deve ao fato de que embora tenha travado contato com o espólio intelectual de Nina Rodrigues ainda na Bahia, portanto bem no início de sua trajetória acadêmica, só quando chega ao Rio de Janeiro, em 1932, que concretiza o reconhecimento de Nina como a sua maior referência nos estudos sobre "o negro”. A partir desse ponto de sua trajetória, Ramos ocupará uma parte robusta do resto de sua (curta) vida reconhecendo a estatura intelectual, a relevância e o pioneirismo de seu trabalho, o exemplo de seu percurso e, last but not least, a sua relação de débito com o "sábio maranhense". Ao mesmo tempo, a cada oportunidade não deixará de apontar as deficiências de conteúdo, de rever os pressupostos teóricos e de propor retificações na obra de seu precursor. Há, não é difícil notar, toda a ambivalência das relações que se estabelecem sobre bases filiais: de um lado a reverência e o respeito ao pai; de outro, o desejo de desvelamento das insuficiências e a reversão da posição original de submissão para a de quem legisla. É de se imaginar o que o jovem Ramos pensou ao ler e reler ao longo dos anos 1920 e 1930, a seguinte passagem de "Totem e tabu":

Um dia, os irmãos outrora expulsos do grupo de origem, se aliaram, mataram e devoraram o pai, e assim puseram fim à horda paterna. Unidos ousaram fazer e levaram a termo aquilo que, individualmente, lhes teria sido impossível. (...) O violento pai primordial era certamente o arquétipo invejado e temido por cada um dos membros do bando de irmãos. E neste instante, no ato de devorar, consumavam a identificação com ele; cada um se apropriava de uma parte de sua força. (...)

O bando dos irmãos amotinados estava governado, em relação ao pai, pelos mesmos sentimentos contraditórios que podemos averiguar como conteúdo da ambivalência do complexo paterno em cada uma de nossas crianças e de nossos neuróticos. Odiavam esse pai (...) mas também o amavam e o admiravam. (Freud, 1913, p. 143-5)

Uma observação importante: naturalmente não se trata aqui de fazer a patografia de Arthur Ramos - incursão sempre temerária e, quase sempre, rica fonte de material ilustrativo da "psicanálise selvagem”. Trata-se, sim, de encontrar uma chave original que permita o acesso ao modo pelo qual Ramos idealizou o

2. Vale ainda mencionar como figura de proa da diáspora rodrigueana Afrânio Peixoto (1876-1947), aluno de Nina Rodrigues e professor de Arthur Ramos. 
seu projeto e desenvolveu a sua obra. Mais do que erudição vazia, o retorno ao contexto histórico de formação da "escola Nina Rodrigues” permite a visualização da tarefa a que seus descendentes se propõem: em resumo, ao vincularem a sua própria atuação intelectual ao nome do mestre, ao mesmo tempo em que recebem o influxo de sua autoridade, sofrem os males da "angústia da influência”, ${ }^{3}$ isto é, temem ter as suas produções engolfadas pela obra do precursor e, por isso mesmo, sob a pena de sucumbirem à sua presença imensa, afetivamente o atacam - devoram a sua obra, digerem as suas premissas e nos devolvem um produto renovado. Nada mais antropofágico, no sentido dado pelo modernismo, do que a apropriação de Nina Rodrigues por Arthur Ramos e seus irmãos; nada mais característico da miscelânea de pensadores da qual Ramos se serviu para elaborar as suas idéias e a liberdade com que leu Freud e seus discípulos, do que a antropofagia de 1922.

O presente trabalho apresentará o que, sob certa perspectiva, são passos cruciais de Arthur Ramos na composição de seu corpus teórico, a saber:

1) A concepção em Primitivo e loucura (1926), de seu projeto básico, ao qual permanecerá vinculado ao longo do desenvolvimento posterior de toda a sua obra.

2) O estabelecimento e fixação de Nina Rodrigues como precursor.

3) A revisão da obra de Nina Rodrigues, especialmente no que tange ao tópico "raça".

4) A sua contribuição etnográfica original, para a qual a psicanálise desempenhou papel determinante.

\section{Aprendiz de feiticeiro}

Os depoimentos sobre Arthur Ramos são invariavelmente repletos de loas à sua precocidade e capacidade intelectuais. ${ }^{4}$ É bem verdade que boa parte desses depoimentos se deu em contextos comemorativos nos quais o que se podia esperar era exatamente um corolário sem fim de qualidades; outros foram colhidos

3. A “angústia da influência” é um conceito elaborado pelo crítico literário Harold Bloom em vários de seus livros (1991a, 1991b, 1992, 1995), cujas aplicações não se restringem ao campo da literatura. Fundamentalmente, a sua idéia é a de que um autor "forte” é constituído sempre das relações com seu antecessor, isto é, constitui sua própria obra, e a necessidade de originalidade que lhe é inerente, pela “desleitura” da obra de sua maior influência teórica.

4. Um bom apanhado desses depoimentos está em Teixeira et al. (1952) e Sapucaia (2003). 
ainda muito próximos à notícia surpreendente de sua morte, tendo sido, portanto, produzidos sob o calor da comoção ou sob os rigores do constrangimento social. Mas há neles algumas informações que se repetem com alguma insistência e, além disso, parecem encontrar ressonância nos livros de Ramos. Uma das coisas que ficamos sabendo ao lê-los é o fato de ele ter se interessado muito cedo pela psicanálise.

Em sua aplaudida obra de estréia: Primitivo e loucura (1926) - na verdade, sua dissertação de conclusão do curso de medicina - comparece na bibliografia e no corpo da obra, um conjunto significativo de escritos psicanalíticos. É preciso notar que não há a predominância de Freud que, ao contrário do que se poderia esperar, divide humildemente o seu lugar - em importância e extensão - com discípulos e com dissidentes. Entre outros, estão presentes no texto Ferenczi, Jung, Adler, Rank, Abraham, Stekel, Jones e até mesmo Spielrein!

À época desse primeiro texto de mais fôlego, ainda não apareciam em seus escritos uma abordagem mais direta ao "problema do negro". Suas contribuições mais significativas nesse campo ainda teriam que esperar cerca de uma década. Logo após Primitivo e loucura, Ramos publicaria a sua tese de livre docência: Sordície nos alienados: ensaio de uma psicopatologia da imundície (1928), e ainda os seguintes livros: Estudos de psicanálise (1931), Freud, Adler, Jung... (1933), ${ }^{5}$ Psiquiatria e psicanálise (1933b) e Educação e psicanálise (1934). Os títulos não deixam dúvida quanto ao foco dos interesses de Ramos e, lendo algumas dessas obras, é possível testemunhar em seu favor: comparado a contemporâneos também interessados em psicanálise, sua leitura é mais refinada e de aproveitamento mais preciso. ${ }^{6}$ Além disso, temos razões para crer que a inclinação de Ramos pelos autores psicanalíticos não correspondia a um interesse de ocasião; e se a psicanálise o serviu mais tarde, como um instrumento para, por exemplo, pensar a educação das crianças na então Capital Federal, não se deve sucumbir à armadilha de inverter a ordem dos fatores. Em Ramos, o interesse pela psicanálise é genuíno e primário, e não requentado a título de suporte teórico oportunista para a sustentação de tal e qual ideologia. ${ }^{7}$

5. Este livro é na realidade uma reedição do livro de 1931, com o acréscimo de dois novos capítulos. Seu curioso subtítulo - ensaios de psicanálise ortodoxa e herética - endossa a impressão da liberdade com que A. Ramos combina os autores psicanalíticos que lê.

6. Como termo de comparação, podemos tomar o caso de Osório César (1895-1974) que, embora dono de uma obra original e rica em achados, não leu Freud com a mesma atenção com que Ramos o fez.

7. É o que parecem sugerir autores como Russo (2005), quando estende para Arthur Ramos conclusões que talvez digam mais respeito a outros médicos brasileiros. 
Em Primitivo e loucura, um texto inundado de psicanálise, Ramos não menciona uma só vez o negro brasileiro. Sua atenção permanece sobre o que, sob a influência maciça de Lévy-Bruhl, ${ }^{8}$ define como "mentalidade primitiva", expressão tomada deste último. Em síntese, A. Ramos propõe a substituição em psicologia de "selvagem" por "primitivo", pretendendo assim afastar um espectro de associações morais indesejáveis ligado ao primeiro desses termos. Seguindo Lévy-Bruhl, por primitivo se entenderia tão-somente, "os membros das sociedades mais simples que conhecemos". E, já fazendo a costura que caracterizará o seu background teórico, Ramos (1926) apresenta as interseções entre a sociologia e a psicanálise:

Acho que a psicologia poderia englobar na expressão de "primitivo" o conceito de mentalidade atrasada tanto na escala filogenética (raças selvagens que já desapareceram e só conhecidas por documentos históricos, ou as que existem ainda hoje em vários pontos do globo) como na escala ontogenética. E é justamente a psicologia moderna, com o advento da psicanálise, que frisa os pontos de contato entre o selvagem e a criança. (p. 4)

Auxiliado pela psicanálise, Arthur Ramos conservará, com poucas modificações no decurso de seus escritos etnográficos, a seguinte trama conceitual e roteiro metodológico:

a) Há, no mundo, algo chamado "primitivo".

b) As crianças, os loucos, certos neuróticos, a arte, os sonhos e os "povos atrasados” compartilhariam das características desse primitivismo. ${ }^{9}$

c) E, finalmente, não "o negro”, mas parte dos negros trazidos ao Brasil como escravos, seriam oriundos de "culturas atrasadas", sobretudo quando justapostas à cultura do colonizador em geral, e mesmo à de outros povos africanos, também representados pelos assim chamados "negros de nação". ${ }^{10}$

8. Lucien Lévy-Bruhl (1857-1939), filósofo e sociólogo francês foi, ao lado dos autores psicanalíticos, talvez a mais forte influência teórica de Arthur Ramos. Publicou, entre outros livros citados por Ramos em suas obras, La mentalité primitive (1922); sua defesa da idéia de um certo relativismo moral, em oposição à adoção de universais que julgava antropocêntricos (neste caso, a referência era invariavelmente o homem europeu, branco e civilizado), parece ter sido um dos pontos que teria então cativado Ramos.

9. As aproximações entre arte e loucura também foram estudadas no Brasil por outros autores. Entre eles, cabe lembrar o já citado Osório César, que elaborou um trabalho brilhante e pioneiro sobre o tema: A expressão artística nos alienados: contribuição para o estudo dos símbolos na arte (1929). A esse respeito, ver também Dalgalarrondo; Gutman; Oda, (2007).

10. Na terminologia da época, opunha-se os africanos trazidos ao Brasil ("negros de nação") aos negros já nascidos no país ("negros crioulos”). 
d) Ainda, a religiosidade seria um campo privilegiado para o estudo do grau de avanço cultural de um determinado povo. Seria, também, terreno fértil para as análises do fenômeno de "aculturação", isto é, o movimento de absorção de uma cultura por outra, dando origem a um híbrido cultural que caracterizaria o povo brasileiro.

e) Do ponto de vista filogenético, então, teríamos além dos símbolos e expressões religiosos, o folclore, cujas manifestações populares ganham contornos de destaque na obra de Ramos.

Este último item corresponde àquela que seria a sua contribuição original neste primeiro escrito mais sólido: a criação do conceito de "inconsciente folclórico”. Com ele, Ramos testa o estatuto das relações entre, de um lado, o sujeito e o seu psiquismo individualizado e, de outro, um conjunto vivo, gigantesco e permanente, que ao mesmo tempo abastece e é abastecido pelos indivíduos. O folclore, largamente pesquisado em alguns de seus livros, ${ }^{11}$ seria a expressão mais palpável desse "inconsciente coletivo", ${ }^{12}$ muito pouco palpável por definição. Diz Ramos (1926):

Além das modalidades várias do inconsciente, que se formam na vida individual, há outras que emigram do indivíduo, lhe são anteriores, ou se projetam fora dele.

Assim é que para Jung, o espírito humano não pode ser considerado como um fato isolado, individual, porque de formação coletiva. Há um "inconsciente ancestral", ou "superinconsciente", formado de estratificações sucessivas que se depositaram no psiquismo humano no correr das idades. (...)

A esse inconsciente impessoal que opera em função do tempo se junta outro, também impessoal, que perambula em estado atual, através da massa gregária. É o “inconsciente interpsíquico", que explica os fatos de

11. Especialmente $O$ folclore negro do Brasil: demopsicologia e psicanálise (1935) e Estudos de folclore (1951).

12. A influência de Jung é explícita, sendo às vezes tentador entender o "inconsciente folclórico" de Ramos como uma variação, vertente ou corruptela do "inconsciente coletivo" do psiquiatra e psicanalista suíço. Em Jung (1916), lê-se: "Temos que distinguir o inconsciente pessoal do inconsciente impessoal ou suprapessoal. Chamamos este último de inconsciente coletivo, porque é desligado do inconsciente pessoal e por ser totalmente universal; e também porque seus conteúdos podem ser encontrados em toda parte, o que obviamente não é o caso dos conteúdos pessoais” (p. 103).

Contudo, quando se observa com cuidado o que descreve Ramos sobre o "inconsciente folclórico", é possível notar que ele o diferencia tanto do "inconsciente coletivo" quanto do "inconsciente interpsíquico", pretendendo que o seu conceito englobe os dois. Ver também Pereira; Gutman (2007). 
intermentalidade, interpsicologia melhormente estudados na psicologia das multidões e nas psicoses gregárias. (...).

Por uma questão didática, poder-se-iam englobar as duas noções num conceito único, o inconsciente folclórico, que faz lembrar não só as influências ancestrais, como as que sobem da massa gregária. (p. 86-9)

O conceito de inconsciente folclórico, tão inflacionado quanto produtivo, permitirá, ainda, o acréscimo de mais um tópico ao roteiro de Ramos:

f) Os elementos inconscientes ancestrais estarão, por assim dizer, sempre prontos para emergir nos pensamentos e ações do homem dito civilizado. Segundo essa diretriz, as festas folclóricas seriam ocasiões especialmente reveladoras do primitivismo adormecido e, assim, palco de manifestações desmedidas, de danças despudoradas e de moralismo amansado.

\section{Os africanos no Brasil}

Em mais de uma ocasião, ${ }^{13}$ Arthur Ramos (1939b) afirmou que o seu interesse e contato com os trabalhos de Nina Rodrigues sobre o negro no Brasil datam de 1926. Diz ele:

Em 1926, começamos a reunir, na Bahia, material de estudo sobre o Negro. Filiado à escola de Nina Rodrigues, como médico legista do Instituto que tem o nome do mestre baiano, encetamos pesquisas nos candomblés baianos, que deram origem aos seguintes trabalhos: Os horizontes míticos do negro da Bahia (1932); A possessão fetichista na Bahia (1932); Os instrumentos musicais dos candomblés da Bahia (1932); O mito de Yemanjá (1932); O negro na evolução social brasileira (Conferência na Universidade do Rio de Janeiro, 1933); As religiões negras no Brasil (Curso realizado em setembro de 1934). (p. 203)

Então, apesar de seu interesse pelo material etnográfico produzido pelo "sábio baiano" 14 coincidir em data com a publicação de Primitivo e loucura, suas próprias

13. Por exemplo, em Loucura e crime: questões de psiquiatria, medicina forense e psicologia social (1937) e em O negro na civilização brasileira (1939).

14. Não deve passar despercebida a opção de nomear "baiano" o mestre, como se sabe, na verdade maranhense; da mesma forma, nomeava-se assim Arthur Ramos, embora não fosse segredo que tivesse nascido na pequena cidade de Pilar - Alagoas. É possível especular que a alcunha "baiano”, além de vincular os seus detentores a um dos dois grandes centros formadores de médicos no Brasil à ocasião (o outro era o Rio de Janeiro), parecia fornecer um traço identitário comum. 
publicações sobre o tema antecedem pouco a publicação de $O$ negro brasileiro (1934), situando-se na mesma década de $1930 .{ }^{15}$

Há, portanto, dois períodos lacunares nos estudos iniciados por Nina Rodrigues: o primeiro estaria entre a sua morte, em 1906, e o interesse de A. Ramos por seu espólio teórico em 1926; o segundo, entre o seu mencionado interesse e as suas publicações dos anos 1930.

O encontro de Ramos com Nina é narrado de modo quase épico, com tintas dramáticas e com certo apelo sobrenatural pelo próprio Ramos, ou por terceiros. O pano de fundo do drama encenado no encontro entre os dois, é uma suposta maldição destinada àquele que ousasse violar o túmulo do "sábio baiano", exumando os seus escritos sobre o negro. Homero Pires, prefaciando, em 1933, o livro Os africanos no Brasil - publicação póstuma daquele que deveria ser o primeiro volume da obra iniciada por N. Rodrigues, e que, se concluída fosse receberia como título O problema da raça negra na América Portuguesa - narra assim, a maldição:

Este livro é como o tesouro dos Niebelungen, guardado por Fafnir: trazia a desgraça àquele que consigo o retivesse.

Bem adiantada já estava a sua impressão na Bahia, (...) quando, em 1906, o seu preclaro autor morreu inopinadamente em Paris. Se bem que doentio, Nina Rodrigues se finou a bem dizer de repente.

O mestre, porém, deixara discípulos. Um destes, e dos mais ilustras, Oscar Freire, chamou a si a tarefa de entregar ao público a obra interrompida. Foramlhe confiados os capítulos impressos, originais, notas, vasta documentação fotográfica.

(...) Oscar Freire se transferiu para S. Paulo, e consigo carregou todo esse depósito. Sobreveio a morte ainda mais inesperada de Oscar Freire.

(...) Há vinte e seis anos que esta obra se começou a imprimir, para não mais se lhe tocar, permanecendo assim longamente trancada e interrompida pela superstição e pela morte.

Ninguém lhe queria por as mãos, com receio dos seus nefastos sortilégios. (Pires, apud Nina Rodrigues, 1906)

Arthur Ramos conta a sua versão da história, também com toques de realismo fantástico:

15. A preocupação de Ramos com as datas se justifica por um debate, acirrado e polêmico, que atravessou os anos 1930, em torno do título de iniciador dos estudos sobre o negro no Brasil, disputando o posto a "Escola de Nina Rodrigues” e a Escola de Recife” (leia-se Ulisses Pernambucano como precursor e Gilberto Freyre como voz forte). 
O assunto tinha ficado sepultado nas velhas pastas do Mestre baiano, no seu Instituto da Bahia. Uma lenda estúpida começara a tomar vulto. $\mathbf{O}$ arquivo de Nina Rodrigues era tabu. As suas notas, as suas observações sobre as religiões, a vida social, a linguagem, o folclore dos negros do Brasil e que ficaram dormindo em pastas preciosas, não poderiam ser revolvidas! Sobre elas se acumulasse a poeira dos tempos. Amarelecessem as folhas de papel escritas da própria mão do mestre. Ninguém tocasse naquilo. Sobre a cabeça dos imprudentes desceria a cólera de Exu, de Xangô, de outros orixás poderosos... E um temor supersticioso envolveu o arquivo, e a lenda era murmurada nos corredores do Instituto, na Bahia. (Ramos, 1937a, p. 202; grifos nossos)

Como pode ser interpretada essa perspectiva dos fatos, na qual é possível perceber, por parte de Ramos, um júbilo no qual se misturam o combate a crendices e à assunção (ao lado da espécie de irmão mais velho que era Afrânio Peixoto) à posição do pai? Se por um lado há o ato afirmativo e ousado de se coroar com as próprias mãos, há também toda a ambivalência implicada em manusear um "tabu".

Alguns comentadores da obra de Ramos, especialmente Corrêa (1998), parecem ver em sua filiação voluntária a Nina Rodrigues algo próximo a um "golpe de mestre" autopromocional: o nome do mestre na fachada externa e, do lado de dentro, torções tais na obra do mestre a ponto de torná-la "irreconhecível”. Não sei se podemos partilhar de tal opinião. É certo que Nina não é exatamente, ou tão-somente, aquilo que Ramos diz ser o corpus teórico do mestre; mas que tipo de fidelidade se poderia esperar de um personagem como Ramos, que é, também, um autor forte? Do mesmo modo que N. Rodrigues se valeu dos pressupostos teóricos de sua época, A. Ramos leu a obra de seu precursor com os pés plantados na década de 1930 no Brasil, com a sociologia de Lévy-Bruhl e, não menos importante, com a psicanálise de Freud.

Há, enfim, em Arthur Ramos, essa mistura tão característica da elaboração de uma herança teórica: a profanação e respeito pela memória do antecessor. Seguindo atentamente os seus passos, verifica-se que ele, em linhas gerais, adotou a metodologia utilizada por Nina Rodrigues, ${ }^{16}$ que é, em síntese:

a) A elaboração de um inventário das “raças” negras que chegaram ao Brasil;

b) o estudo da origem dessas raças em seu ponto de origem no continente africano;

16. Como nota Campos (2004), que reforça a impressão de “continuidades importantes” entre mestre e discípulo, embora também tenha percebido a "tensão existente entre o elogio à iniciativa de Nina Rodrigues de assumir e estudar a questão do negro e o desejo de apontar e criticar os problemas criados pelas teorias do século XIX que informaram o seu trabalho, superando-os a partir de uma terminologia científica mais moderna” (Campos, 2004, p. 158). 
c) a construção da hipótese de que há níveis diferentes entre essas raças diversas;

d) o levantamento etnográfico de forte cunho empírico, do destino dessas raças no Brasil em gerações sucessivas.

\section{O retorno a Nina Rodrigues}

Se abrir mão do espólio de Nina Rodrigues equivaleria a desfazer-se de parte significativa de sua própria substância, ao retornar à obra do "sábio baiano", Arthur Ramos o soube fazer de modo renovador. Definitivamente, Ramos não era um repetidor dos achados de Nina; partiu da obra do mestre para constituir uma obra vasta e autoral. A começar por ampliar e rever os dados etnográficos colhidos na pesquisa de campo e, também, acrescidos de toda sorte de material provindo de músicas, histórias, lendas, hábitos etc.

Na pesquisa realizada por Nina Rodrigues, os resultados indicavam que os africanos introduzidos no Brasil provinham de três grupos "raciais” distintos:

a) Os de culturas sudanesas (iorubás);

b) os de culturas guineano-sudanesas (islamizados);

c) os de culturas bantus.

Na perspectiva de Nina, “os sudaneses” seriam superiores aos demais, o que deveria implicar na absorção desses últimos pelos primeiros.

De acordo com Ramos, ao contrário, para além de qualquer pretensão em determinar a identificação (ou mesmo a existência) de "raças puras", ${ }^{17}$ não existiriam diferenças raciais, mas diferenças culturais, sendo essa a sua crítica mais central às premissas de Nina. No total, A. Ramos (1942) aponta "três postulados falsos” em N. Rodrigues, a saber:

a) A tese das desigualdades raciais;

b) a tese da inferioridade e da degenerescência do mestiço brasileiro;

c) a tese da responsabilidade atenuada dos negros, índios e mestiços brasileiros, decorrente dos dois postulados iniciais. (p. 208)

17. Sobre isso, escreve Ramos (1942): “Quando falamos de 'contatos de raça', pressupomos a existência de raças puras, ou de indivíduos representantes de stocks raciais puros ou relativamente puros, isto é, sem mestiçagem, que se puseram em contato biológico com outros indivíduos representantes de outros stocks raciais também puros ou relativamente puros. Mas aqui nos defrontamos com uma dificuldade insuperável: é que não encontramos hoje na face da terra stocks puros, sem cruzamentos com outros, imunes de todo contato” (p. 199-200). 
A proposta de substituição da idéia de desigualdades raciais pela de diferenças culturais é notada por outros comentadores (Campos, 2004; Corrêa, 1998; Martínez-Echazábal, 1996) como o fulcro da revisão elaborada sobre o segmento etnográfico da obra de Nina. Esses mesmos comentadores - e nós estamos de acordo com esse ponto de vista - notam que se Ramos procura expulsar a noção de "raça” pela porta da frente, ela retorna pela porta dos fundos. Isto porque, ao afirmar que há níveis diferentes de cultura entre, por exemplo, negros sudaneses e negros bantus, e entre os sudaneses e "brancos", recorre a critérios "raciais" (como a presença de tais ou quais traços físicos) para determinar quais os indivíduos pertencentes a um ou a outro ramo cultural.

A essa percepção, poderíamos acrescentar duas outras. Primeiro, do mesmo modo que não parece tarefa possível separar "raças puras" umas das outras, também parece impossível delimitar com precisão “culturas distintas”. ${ }^{18}$ Segundo, quaisquer que sejam os critérios utilizados para a delimitação dessas diferenças culturais, é passível da crítica de qualquer estudante de antropologia dos dias de hoje, a idéia de que há culturas "superiores” ou mais “adiantadas” do que outras.

\section{E a psicanálise?}

Na medida em que a etnografia começava a surgir nos escritos do início da década de 1930, a psicanálise perdia terreno, desaparecendo quase completamente a partir do final dessa mesma década. Uma das poucas vezes em que ainda aparece nas páginas de Ramos, é sob a forma de queixa, assim formulada por ele:

Já tenho mostrado, em mais de uma oportunidade, o trágico destino de certas expressões, de legítimas origens científicas, e que caíram, entre nós, em absoluto desprestígio. "Psicanálise” é uma delas. A princípio hostilizada, virou moda depois. Todo o mundo, do advogado pedante ao adolescente convencido, tinha forçosamente que citar Freud e falar em "psicanálise". A pobrezinha virou panacéia. Foi parar nas revistas ilustradas, onde se fundaram "consultórios" de

18. Em A aculturação negra no Brasil (1942), Ramos recupera o seguinte episódio narrado por Nina Rodrigues em $O$ animismo fetichista dos negros baianos (1896-7), no qual supostamente estaria demonstrada a diferença de crença religiosa entre africanos e negros nascidos no Brasil: “A distinção entre candomblés africanos e candomblés nacionais é hoje geralmente conhecida. Um dia inquiri de uma velhinha africana que assistia de longe as danças sagradas de Gantois, se ela não tinha santo e porque não ia dançar. Respondeu-me que o seu terreiro era de gente da Costa (Africanos) e ficava no bairro de Santo Antônio; que o terreiro de Gantois era terreiro de gente da terra (creoulas e mulatas)". 
psicanálise. O caminho estava traçado. Frenologia dos novos tempos, o seu reduto tinha que ser a banca dos quiromantes. "Professor" Sinval, Madame Grega e quantas outras madames anunciam a psicanálise.

Naturalmente não interessaria a ninguém ser associado a "professores Sinvais" e "Madames Gregas”, mas a adesão e o relativo abandono da psicanálise é um capítulo complexo na biografia de Arthur Ramos. No início, tínhamos o rapaz recém-egresso da faculdade, entusiasmado e orgulhoso das cartas trocadas com Freud. E, para além do entusiasmo, sempre disposto a defender a inclusão maciça da psicanálise entre os seus referenciais teóricos de então. Este interesse não deixou de crescer, como o provam os livros do início da década de 1930. Em O negro brasileiro (1934), temos a expressão máxima, nos escritos de Ramos, do encontro entre o interesse pela etnografia e o peso das leituras psicanalíticas. O livro é dividido em duas grandes partes: na primeira, Ramos (1934) discorre sobre a origem e destino das raças introduzidas no Brasil; na segunda, ele realiza o que chama de "exegese psicanalítica”, grosso modo, a interpretação de fatos de religião e/ou do folclore à luz do instrumental teórico da psicanálise. Uma boa ilustração dessa tentativa de junção está no capítulo intitulado "O ciclo da mãe: os mitos das águas”, no qual Ramos identifica Iemanjá à mãe edipiana:

As deusas-mães chegaram ao Brasil através de Iemanjá. E podemos aventar a hipótese que essa atuação tão forte de Iemanjá no espírito dos negros reside nos seus motivos francamente edipianos (...). Iemanjá é a imago materna (...).

Nos candomblés de caboclo, ela se torna a sereia, e como tal, é representada por uma figura metade peixe, metade mulher, feições lindas e cabelos longos. (...) O primeiro elemento inconsciente da atração materna está nos seus atributos de beleza, a exigir do apaixonado todo um adereço de boudoir: sabonetes, frascos de perfume, fitas, pentes etc. E os cânticos são lânguidos e doces, evocando-lhe a beleza interdita e fatal, a beleza inacessível aos seus filhos, os angustiados Édipos deste ciclo de atrações e tabus. (p. 215-8)

A presença robusta da psicanálise como matriz conceitual privilegiada nas análises de A. Ramos, provocou muita reação por parte de seus críticos. ${ }^{19} \mathrm{O}$ tom

19. Entre eles, o ilustre Gilberto Freyre, que a respeito da ligação de Ramos com a psicanálise, disse: "Lembro-me que fui obrigado a criticar o primeiro programa apresentado por Arthur Ramos (para a cátedra de psicologia da Universidade do Distrito Federal); a meu ver, excessivamente sobrecarregado de psicanálise. Ramos não gostou da crítica: era então um apaixonado da psicanálise (...).

Sucedeu em Arthur Ramos o que era natural que sucedesse em um homem de inteligência tão marcada pelo equilíbrio científico: o fervor psicanalítico foi nele superado à proporção que sua 
com que alguns se manifestaram permitia depreender que inferências psicanalíticas não eram, então, bem vindas em livros de antropologia. Apesar disso, Ramos defende a sua abordagem em um apêndice de 1940 à segunda, e definitiva, edição de $O$ negro brasileiro: ${ }^{20}$

O mais volumoso dos argumentos (críticos) foi contra o método psicanalítico para a interpretação da cultura, empregado pelo autor como "hipótese de trabalho". E ao "evolucionismo" freudiano, contrapôs-se o emprego dos métodos das novas escolas histórico-culturais. Passo ao largo sobre juízos apressados de algumas pessoas, ignorantes não só do que seja a psicanálise, como do que seja o método histórico-cultural, nos seus desenvolvimentos mais recentes e suas aplicações ao problema da cultura.

(...) No que se refere à posição da psicanálise, aceito algumas restrições, como as que lhe trouxe, por exemplo, Malinowski, sem sair da sua posição metodológica. (...)

A interpretação psicanalítica continua legítima mesmo dentro da relatividade da evolução. Em determinados ciclos de cultura, podemos nos socorrer legitimamente da interpretação psicanalítica, na indagação do porquê da personalidade cultural. (Ramos, 1940c, p. 325-6)

Ramos recorre a Malinowski para elaborar a defesa de sua "posição metodológica atual”, aproveitando na leitura que faz do autor, a idéia de que são possíveis, e pertinentes, análises de orientação teórica diversa à antropologia, desde que "dentro de determinados ciclos de cultura”. Assim, não haveria qualquer problema em, por exemplo, pensar freudianamente os complexos familiares, desde que esses não fossem entendidos como causa da cultura, mas, ao contrário, produtos dela. De acordo com Ramos (1940c), chegar-se-ia assim a uma "conciliação metodológica”: empregar a psicanálise "não dentro dos primitivos critérios de evolução uniforme, gradual, unilateral, universal, mas dentro das estruturas culturais respectivas” (p. 237).

De certo modo, A. Ramos era pressionado pelos antropólogos por servir a dois patrões. Esta tentativa de conciliação metodológica foi a sua última tentativa de colocar em diálogo a "paixão pela psicanálise” (como disse G. Freyre), à solidez dos estudos do onipresente Nina Rodrigues. A melhor versão dessa conciliação

visão de psicólogo se aprofundou e que suas pesquisas etnológicas se alargaram” (Freyre, apud Sapucaia, 2003, p. 58). Há outros momentos em que Freyre é ainda mais direto, como que se gabando de ter, por assim dizer, livrado Ramos da psicanálise.

20. A $5^{\text {a }}$ edição do livro, que nos serve de referência neste trabalho, ao lado da $1^{\text {a }}$ edição da obra, reproduz integralmente a $2^{\mathrm{a}}$ edição. Vale notar que a partir desta $2^{\mathrm{a}}$ edição, desaparece do subtítulo original - Etnografia religiosa e psicanálise - a palavra “psicanálise”. 
é dada pela idéia de que um sujeito não é efeito apenas de um inconsciente individual, mas de um "inconsciente coletivo" que, como vimos, Ramos prefere incorporar ao seu conceito de "inconsciente folclórico". Assim, por um lado, Ramos deseja mostrar que cada sujeito, e em especial "o brasileiro”, é produto de todo o conjunto de características e produtos culturais depositados ao longo dos séculos de constituição do Brasil.

Ramos, cuja contribuição e cujas "heresias metodológicas" ainda merecem mais estudo, deixa a sugestão de um modo de composição psíquica que teria observado nos brasileiros: não uma "raça" opondo-se a "outra”, mas uma camada primitiva (em permanente comunicação com o inconsciente folclórico), presente em todos, pronta a emergir no civilizado e "a céu aberto" em expressões culturais e religiosas, poderia ter dito ele, mais básicas.

Onde fica a Rua Professor Arthur Ramos?

\section{Referências}

BLoom, Harold. A angústia da influência: uma teoria da poesia. Rio de Janeiro: Imago, 1991a.

__ Cabala e crítica. Rio de Janeiro: Imago, 1991b.

1992.

Poesia e repressão: o revisionismo de Blake a Stevens. Rio de Janeiro: Imago,

Um mapa da desleitura. Rio de Janeiro: Imago, 1995.

CAmpos, Maria J. Arthur Ramos: luz e sombra na antropologia brasileira. Uma versão da democracia racial no Brasil nas décadas de 1930 e 1940. Rio de Janeiro: Biblioteca Nacional, 2004.

CorrêA, Mariza. As ilusões da liberdade: a escola Nina Rodrigues e a antropologia no Brasil. Bragança Paulista: EDUSF, 1998.

Dalgalarrondo, Paulo; Gutman, Guilherme; Oda, Ana G. R. Osório Cesar e Roger Bastide: as relações entre arte, religião e psicopatologia. Revista Latinoamericana de Psicopatologia Fundamental, São Paulo, v. X, n. 1, p. 101-17, mar.2007.

Faillage, Vera L. M. Arquivo Arthur Ramos: inventário analítico. Rio de Janeiro: Biblioteca Nacional, 2004.

Freud, Sigmund (1913). Totem e tabu. Algunas concordâncias en la vida anímica de los salvajes y de los neuróticos. In: Obras Completas. Buenos Aires: Amorrortu, 1993. v. XIII.

Jung, Carl G. (1916). Psicologia do inconsciente. Petrópolis: Vozes, 1983. 
Lody, Raul. Coleção Arthur Ramos. Rio de Janeiro: Funarte, 1987.

MartíneZ-EchazÁBAL, Lourdes. O culturalismo dos anos 30 no Brasil e na América Latina: deslocamento retórico ou mudança conceitual? In: MaIo, Marcos C. e SANTos, Ricardo V. (orgs.). Raça, ciência e sociedade. Rio de Janeiro: FIOCRUZ/CCBB, 1996.

Nina-Rodrigues, Raimundo (1896-7). O animismo fetichista dos negros baianos. Rio de Janeiro: Biblioteca Nacional/UFRJ, 2006.

(1906). Os africanos no Brasil. São Paulo: Companhia Editora Nacional, 1932.

Pereira, Mario E. C.; Gutman, Guilherme. Primitivo e loucura, ou o inconsciente e a psicopatologia segundo Arthur Ramos. Revista Latinoamericana de Psicopatologia Fundamental, São Paulo, v. X, n. 3, p. 517-25, set.2007.

Ramos, Arthur. Primitivo e loucura (tese apresentada à Faculdade de Medicina da Bahia), Salvador, Imprensa Oficial do Estado, 1926.

Freud, Adler, Jung...: ensaios de psicanálise ortodoxa e herética. Rio de Janeiro: Guanabara, 1933a.

Psiquiatria e psicanálise. Rio de Janeiro: Guanabara Koogan, 1933b.

O negro brasileiro: etnografia religiosa e psicanálise. Rio de Janeiro: Civilização Brasileira, 1934.

(1935). O folclore negro do Brasil: demopsicologia e psicanálise. 2. ed. ilustrada e revista. Rio de Janeiro: Casa do Estudante do Brasil, 1954.

(1936a). Introdução à Psicologia Social. 3. ed. Rio de Janeiro: Casa do Estudante do Brasil, 1957.

O problema psico-sociológico do judeu. In: Регхото, Afranio et al. Os judeus na história do Brasil. Rio de Janeiro: Uri Zwerling, 1936b. p. 117-22.

Loucura e crime: questões de psiquiatria, medicina forense e psicologia social. Porto Alegre: Globo, 1937a.

(1937b). As culturas negras no Novo Mundo. 4. ed. São Paulo: Companhia Editora Nacional, 1979.

(1939a). A criança problema: a higiene mental na escola primária. 4. ed. Rio de Janeiro: Casa do Estudante do Brasil, 1954. do Brasil, 1956.

(1939b). O negro na civilização brasileira. Rio de Janeiro: Casa do Estudante

Culturas negras: problemas de aculturação no Brasil. In: O negro no Brasil: trabalhos apresentados ao $2^{\circ}$ Congresso Afro-brasileiro (vários autores). Rio de Janeiro: Civilização Brasileira, 1940a. p. 147-59.

Nina Rodrigues e os estudos negro-brasileiros. In: O negro no Brasil: traba- 
lhos apresentados ao $2^{\circ}$ Congresso Afro-brasileiro (vários autores). Rio de Janeiro: Civilização Brasileira, 1940b. p. 337-9.

(1940c). O negro brasileiro: etnografia religiosa. 2/5. ed. Rio de Janeiro: Graphia, 2001.

A aculturação negra no Brasil. São Paulo: Companhia Editora Nacional, 1942.

(1943). Introdução à antropologia brasileira: as culturas negras. Rio de Janeiro: Casa do Estudante do Brasil, s/data. v. III.

As ciências sociais e os problemas de após-guerra. Rio de Janeiro: Companhia Editora Nacional, 1944a.

Las poblaciones del Brasil. México: Fondo de Cultura Económica, 1944b.

Estudos de folclore: definição e limites. Teorias de interpretação. 2. ed. Rio de Janeiro: Casa do Estudante do Brasil, 1951.

(1952). A mestiçagem no Brasil. Maceió: EdUFAL, 2004.

Ramos, Luiza; Ramos, Arthur. A renda de bilros e sua aculturação no Brasil: nota preliminar e roteiro de pesquisas. Rio de Janeiro: Publicações da Sociedade Brasileira de Antropologia e Etnologia, 1948.

Russo, Jane. Júlio Porto-Carrero: a psicanálise como instrumento civilizador. In: DuARTE, Luiz F. D.; Russo, Jane; VenÂncio, Ana T. (orgs.). Psicologização no Brasil: atores e autores. Rio de Janeiro: Contra Capa, 2005. p. 127-49.

SAPUCAiA, Antonio (org.). Relembrando Arthur Ramos. Maceió: edUFAL, 2003.

SCHREINER, Alexandre. Uma aventura para o amanhã: Arthur Ramos e a neuro-higiene infantil na década de 1930. In: Duarte, Luiz F. D.; Russo, Jane; VenÂncio, Ana T. (orgs.). Psicologização no Brasil: atores e autores. Rio de Janeiro: Contra Capa, 2005. p. 15166.

Teixeira, Anísio et al. Arthur Ramos. Rio de Janeiro: Ministério da Educação e Saúde, 1952.

\section{Resumos}

Abordaje de las relaciones entre psicoanálisis y el concepto de "raza" en el Brasil, en la obra de Arthur Ramos. Estudio de la relación entre los trabajos etnográficos de Nina Rodrigues y de Arthur Ramos. Investigación de la formación étnica, religiosa y cultural de lo brasileño.

Palabras claves: Psicoanálisis, raza, Arthur Ramos, cultura 
Approche des rapports, au Brésil, entre la psychanalyse et le concept de "race" dans l'oeuvre de Arthur Ramos. Étude du rapport entre les travaux ethnographiques de Nina Rodrigues et de Arthur Ramos. Recherche sur la constitution ethnique, religieuse et culturelle du brésilien.

Mots clés: Psychanalyse, race, Arthur Ramos, culture

Approach to the relationships in Brazil between psychoanalysis and the concept of "race" in the works of Arthur Ramos. Study of the relationships between Nina Rodrigues' ethnographic findings and Arthur Ramos' works. Survey on the Brazilian ethnic, religious and cultural composition.

Key words: Psychoanalysis, race, Arthur Ramos, culture

\section{GUILHERME GutMan}

Médico psiquiatra e psicanalista; doutor em Saúde Coletiva pelo Instituto de Medicina Social - Universidade Estadual do Rio de Janeiro ( Rio de Janeiro, Brasil); professor do Departamento de Psicologia da PUC-RJ (Rio de Janeiro, RJ, Brasil).

Rua Visconde de Pirajá, 82/s.704 - Ipanema

22410-000 Rio de Janeiro, RJ, Brasil

e-mail: guilhermegutman@gmail.com 